\title{
A Study to Determine the Inheritance Pattern of Characteristics of Handwriting between Parents and Off-springs
}

\author{
Kiran $\mathrm{P}^{* 1}$ and Sridhar $\mathrm{D}^{2}$ \\ ${ }^{1}$ Assistant Professor, Department of Forensic Science, Jain University, Bangalore, India \\ ${ }^{2}$ Under Graduate, Department of Forensic Science, Jain University, Bangalore, India
}

*Corresponding author: Kiran P, Assistant Professor, Department of Forensic Science, Jain University, Bangalore, India, Tel: 8971435885, E-mail: peterkiran.a@gmail.com

Citation: Kiran P, Sridhar D (2017) A Study to Determine the Inheritance Pattern of Characteristics of Handwriting between Parents and Off Springs. J Forensic Sci Criminol 5(3): 304

Received Date: November 19, 2016 Accepted Date: August 05, 2017 Published Date: August 08, 2017

\begin{abstract}
Parents are the children's learning models. A preschooler is influenced by the handwriting of his or her parents. He learns to write letters by imitating or copying the letters formed by the parents. When he is satisfied with the way he writes it, how it looks he will begin to write it without paying attention to its details.

After manually analyzing all the 50 samples, there were similarities found between the parents and the off-springs. While analyzing the general correlation of handwriting characteristics between the parents and the off-springs, it was found that there is highest level of similarity in pen lifts and a low level of similarity was found in the pressure applied while writing.

The characteristics like pen lifts, entry strokes, exit strokes, connecting strokes, alignment and shading that show a high level of similarity are class characteristics whereas the handwriting characteristics such as pressure, diacritic of the letter " $\mathrm{t}$ ", loop formed by the letter "e", diacritics of the letter "i" and baseline that show a low level of similarity are individualistic i.e. they vary for each person.
\end{abstract}

Keywords: Inheritance Pattern; Handwriting; Pen lifts; Parents; Off Springs

\section{Introduction}

Parents are the children's learning models. A preschooler is influenced by the handwriting of his or her parents. He learns to write letters by imitating or copying the letters formed by the parents. For example, a son may like the shape of a letter written by his father so he practices making that letter until he thinks it is like his father's. When he is satisfied with the way he writes it, how it looks (because it is like his father), he will begin to write it without paying attention to its details. By repeated attempts to copy this basic pattern the child incorporates the peculiarities of writing of his parents into his writing habits. The better his memory of forms and the more time he spends practicing letter forms written by his parents, the more habitual his movement becomes and the closer the new writing form will be to the parental writing model. This tendency also occurs during adolescence, when the writer is developing and experimenting with his/her writing. As a writer matures he incorporates more individuality in his writing but he is still influenced by the previous writing system features and his writing may very well become a combination of the two. How much of a combination depends upon the writing habits he develops (Morris, 2000). Writing habits of the off-springs are also shaped by genetic factors. These writing habits may include handedness, writing posture, pen position, learning and thinking ability. A few studies have also been done on familial resemblance with respect to hand preference, handwriting posture and specific cognitive abilities [1,2].

A study conducted on resemblance of slant in handwriting of closed genotypic family members in a sample of 360 families, using computational method based on MATLAB, followed by the statistical evaluation of the parameters, showed a significant resemblance of slant in handwriting of offspring's of family members. However, handedness, and gender may be involved in the formation of this behavior. Since handwriting is a complex and multi-causal mechanism [3].

In another study, it was seen that handwriting is one of the acquired characteristics of humans. It is a mixture of nature and nurture. Parents play an important part in teaching pre-writing skills to their children. Genetics also has a role in shaping the writing habits of the writer (such as handedness and handwriting positions). The handwritings of parents and their biological off-springs were examined to determine the inheritance of handwriting features from one generation to the next generation. In this scheme, resemblances in the handwriting features of parents off springs were studied using computational features based on MATLAB 8.3 software [4]. 


\section{Methodology}

This study was conducted in Bangalore city belonging to Karnataka of south Indian region. The method used to collect data was snowball technique. To study the inheritance pattern of characteristics of handwritings between parents and siblings members of the family i.e. Father, mother and the off-springs (family with two off-springs was selected for the study) $[5,6]$.

Handwriting samples from 50 families are collected by requesting each member to write a sample paragraph for minimum of three times. The same writing instrument and paper was provided for each respondent. These samples are analyzed manually using different tools such as a hand magnifier and a stereo microscope and scales to check the degree of similarities in handwriting characteristics between parents and off-springs [7-10].

\section{Result}

From Table 1 and Figure 1, it was seen that there was 76\% similarity in the alignment between the parents and the offsprings. Likewise, similarities were found in characteristics such as baseline (28\%), slant (44\%), entry stroke (80\%), exit stroke (76\%), connecting stroke (70\%), pressure (14\%), pen lifts (76\%), shading (74\%), diacritic “i” (42\%), diacritic "l” (38\%), loop "e" (18\%) and loop "l" (36\%). The highest similarity is found in the entry stroke (initial stroke) whereas the lowest similarity is in the pressure applied while writing.

\begin{tabular}{|c|c|c|}
\hline \multicolumn{3}{|c|}{ General Correlation } \\
\hline Characteristics & Number & Percentage \\
\hline Alignment & 38 & 76 \\
\hline Baseline & 14 & 28 \\
\hline Slant & 22 & 44 \\
\hline Entry Stroke & 40 & 80 \\
\hline Exit Stroke & 38 & 76 \\
\hline Connecting Stroke & 35 & 70 \\
\hline Pressure & 7 & 14 \\
\hline Pen lifts & 38 & 76 \\
\hline Shading & 37 & 74 \\
\hline Diacritics "i" & 21 & 42 \\
\hline Diacritics "t" & 19 & 38 \\
\hline Loops "e" & 9 & 18 \\
\hline Loops "l" & 18 & 36 \\
\hline
\end{tabular}

Table 1: Representing general correlation of handwriting characteristics between parents and off-springs

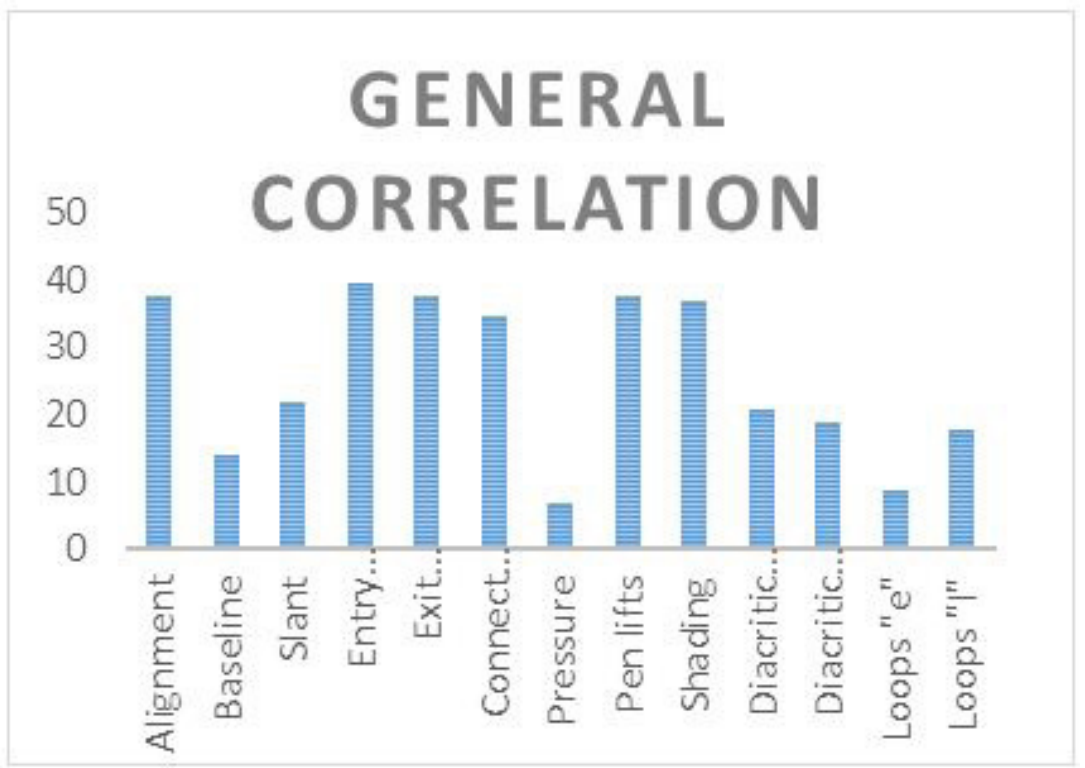

Figure 1: Showing the correlation of various handwriting characteristics between the parents and the offsprings 
From Table 2 and Figure 2, it was seen that there was 79.16\% similarity in the alignment between the mothers and the daughters. Likewise, similarities were found in characteristics such as baseline (62.5\%), slant (75\%), entry stroke (83.33\%), exit stroke (87.5\%), connecting stroke (77.08\%), pressure (29.16\%), pen lifts (79.16\%), shading (79.16\%), diacritic “i” (47.91\%), diacritic "1" (66.66\%), loop "e" (60.41\%) and loop "l" (56.25\%). The highest similarity is found in the exit stroke (terminal stroke) whereas the lowest similarity is in the pressure applied while writing.

\begin{tabular}{|c|c|c|}
\hline \multicolumn{3}{|c|}{ Mother- Daughter } \\
\hline Characteristics & Number & Percentage \\
\hline Alignment & 38 & 79.16 \\
\hline Baseline & 30 & 62.5 \\
\hline Slant & 36 & 75 \\
\hline Entry Stroke & 40 & 83.33 \\
\hline Exit Stroke & 42 & 87.5 \\
\hline Connecting Stroke & 37 & 77.08 \\
\hline Pressure & 14 & 29.16 \\
\hline Pen lifts & 38 & 79.16 \\
\hline Shading & 38 & 79.16 \\
\hline Diacritics "i" & 23 & 47.91 \\
\hline Diacritics "t" & 32 & 66.66 \\
\hline Loops "e" & 29 & 60.41 \\
\hline Loops "l" & 27 & 56.25 \\
\hline
\end{tabular}

Table 2: Representing correlation of handwriting characteristics between mother and daughter

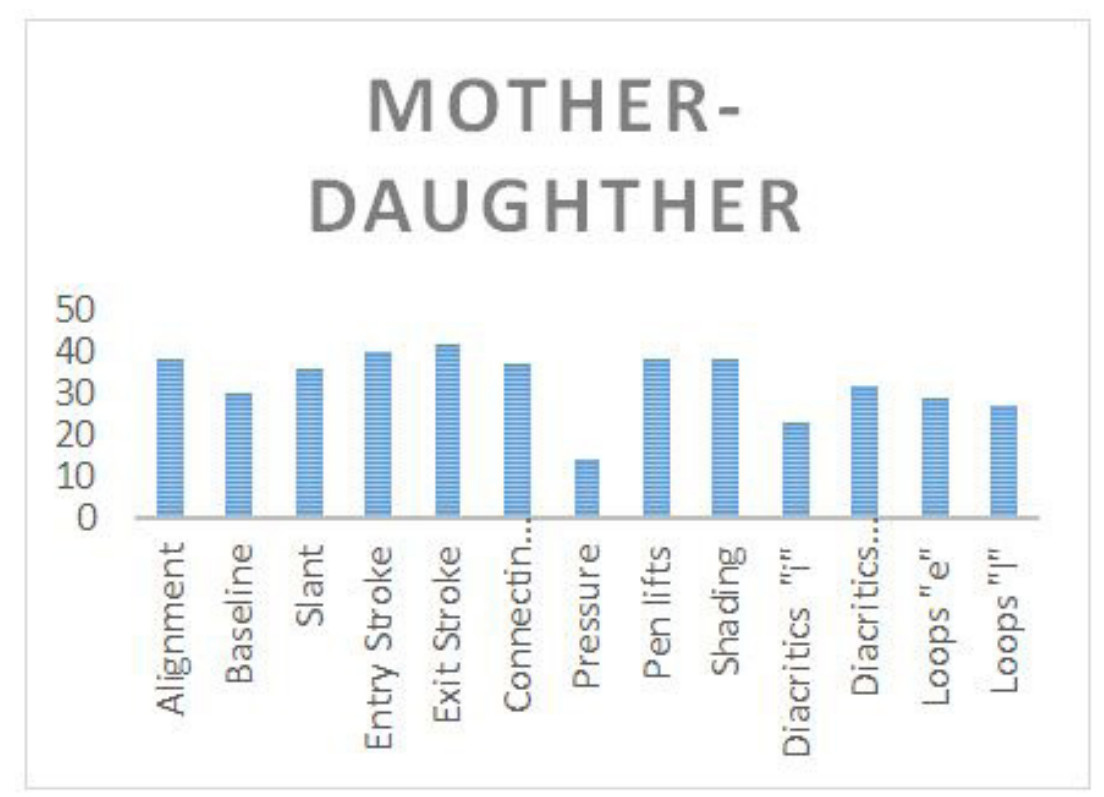

Figure 2: Showing the correlation of various handwriting characteristics between Mother and Daughter

From Table 3 and Figure 3, it was seen that there was $88.46 \%$ similarity in the alignment between the mothers and the sons. Likewise, similarities were found in characteristics such as baseline (59.96\%), slant (65.38\%), entry stroke (90.38\%), exit stroke (90.38\%), connecting stroke (82.69\%), pressure (50\%), pen lifts (86.53\%), shading (86.53\%), diacritic "i" (65.38\%), diacritic "l" (67.30\%), loop "e" $(65.38 \%)$ and loop "l" $(65.38 \%)$. The highest similarity is found in the entry and exit strokes whereas the lowest similarity is in the pressure applied while writing.

\begin{tabular}{|c|c|c|}
\hline \multicolumn{3}{|c|}{ Mother- Son } \\
\hline Characteristics & Number & Percentage \\
\hline Alignment & 46 & 88.46 \\
\hline Baseline & 31 & 59.96 \\
\hline Slant & 34 & 65.38 \\
\hline Entry Stroke & 47 & 90.38 \\
\hline
\end{tabular}




\begin{tabular}{|c|c|c|}
\hline \multicolumn{3}{|c|}{ Mother- Son } \\
\hline Characteristics & Number & Percentage \\
\hline Exit Stroke & 47 & 90.38 \\
\hline Connecting Stroke & 43 & 82.69 \\
\hline Pressure & 26 & 50 \\
\hline Pen lifts & 45 & 86.53 \\
\hline Shading & 45 & 86.53 \\
\hline Diacritics "i" & 34 & 65.38 \\
\hline Diacritics "t" & 35 & 67.30 \\
\hline Loops "e" & 34 & 65.38 \\
\hline Loops "l" & 34 & 65.38 \\
\hline
\end{tabular}

Table 3: Representing correlation of handwriting characteristics between Mother and Son

\section{MOTHER-SON}

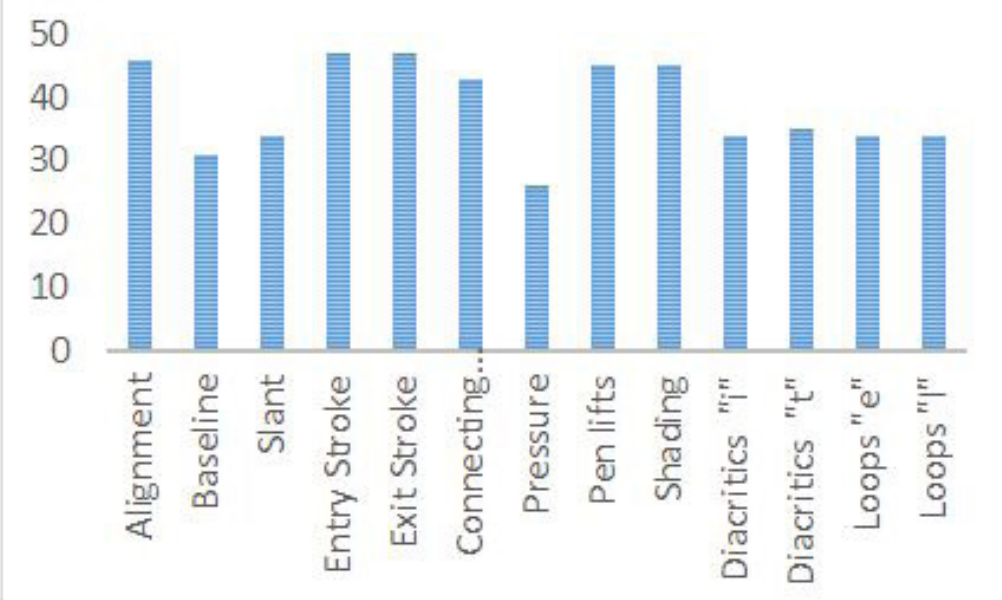

Figure 3: Showing the correlation of various hand writing characteristics between Mother and Son

From Table 4 and Figure 4, it was seen that there was $79.16 \%$ similarity in the alignment between the fathers and the daughters. Likewise, similarities were found in characteristics such as baseline (58.33\%), slant (66.66\%), entry stroke (87.5\%), exit stroke (89.58\%), connecting stroke (72.9\%), pressure (60.41\%), pen lifts (87.5\%), shading (87.5\%), diacritic "i" (64.58\%), diacritic "l" (60.41\%), loop "e" (43.75\%) and loop "l" (52.08\%). The highest similarity is found in the exit stroke whereas the lowest similarity is in the loop formed by the letter " $\mathrm{e}$ ".

\begin{tabular}{|c|c|c|}
\hline \multicolumn{3}{|c|}{ Father-Daughter } \\
\hline Characteristics & Number & Percentage \\
\hline Alignment & 38 & 79.16 \\
\hline Baseline & 28 & 58.33 \\
\hline Slant & 32 & 66.66 \\
\hline Entry Stroke & 42 & 87.5 \\
\hline Exit Stroke & 43 & 89.58 \\
\hline Connecting Stroke & 35 & 72.9 \\
\hline Pressure & 29 & 60.41 \\
\hline Pen lifts & 42 & 87.5 \\
\hline Shading & 42 & 87.5 \\
\hline Diacritics "i" & 31 & 64.58 \\
\hline Diacritics "t" & 29 & 60.41 \\
\hline Loops "e" & 21 & 43.75 \\
\hline Loops "l" & 25 & 52.08 \\
\hline
\end{tabular}

Table 4: Representing correlation of handwriting characteristics between Father and Daughter 


\section{FATHER-DAUGHTER}

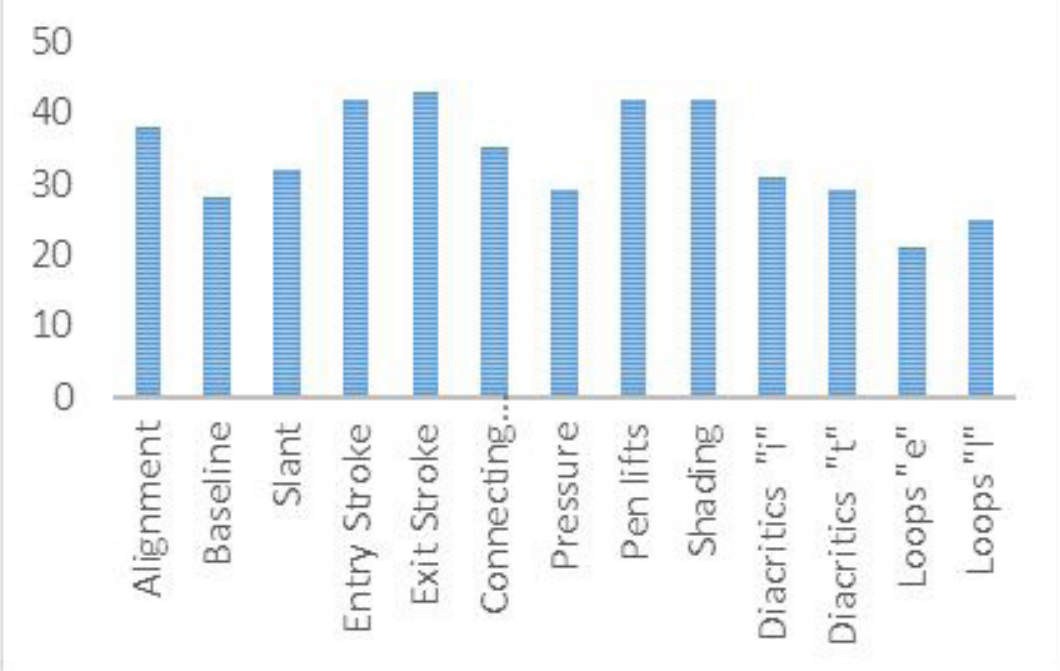

Figure 4: Showing the correlation of various handwriting characteristics between Father and Daughter

From Table 5 and Figure 5, it was seen that there was $84.61 \%$ similarity in the alignment between the fathers and the sons. Likewise, similarities were found in characteristics such as baseline (50\%), slant (73.07\%), entry stroke (92.30\%), exit stroke (88.46\%), connecting stroke (86.53\%), pressure (57.69\%), pen lifts $(86.53 \%)$, shading $(84.61 \%)$, diacritic “i” (71.15\%), diacritic "l” (69.23\%), loop " $\mathrm{e}$ " (48.07\%) and loop "l" (67.30\%). The highest similarity is found in the entry strokes whereas the lowest similarity is in the loop formed by the letter "e".

\section{FATHER-SON}

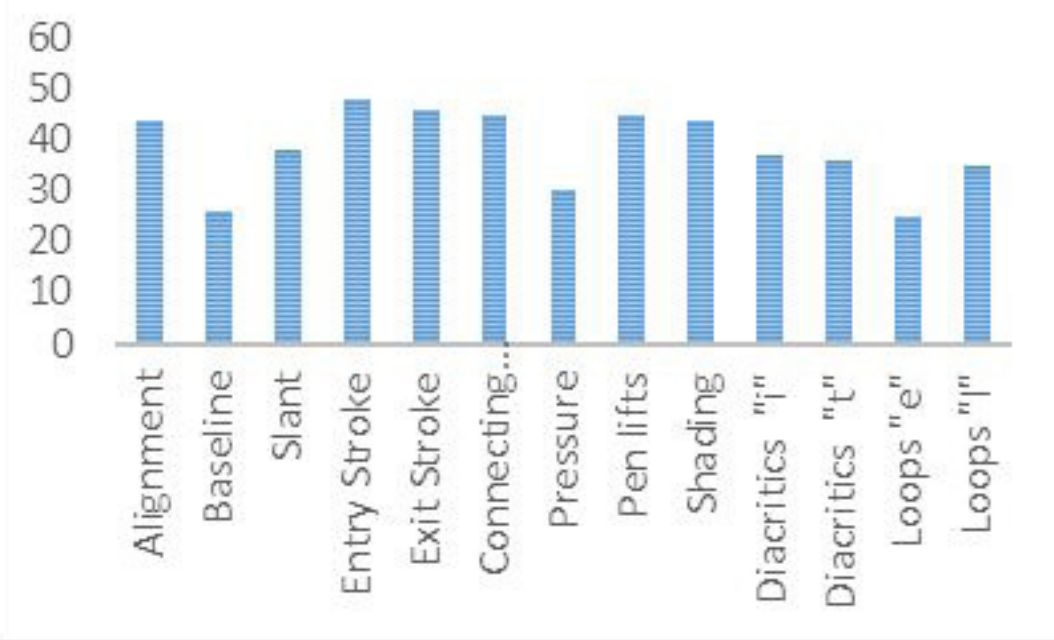

Figure 5: Showing correlation of various handwriting characteristics between Father and Son

\begin{tabular}{|c|c|c|}
\hline \multicolumn{3}{|c|}{ Father- Son } \\
\hline Characteristics & Number & Percentage \\
\hline Alignment & 44 & 84.61 \\
\hline Baseline & 26 & 50 \\
\hline Slant & 38 & 73.07 \\
\hline Entry Stroke & 48 & 92.30 \\
\hline Exit Stroke & 46 & 88.46 \\
\hline
\end{tabular}




\begin{tabular}{|c|c|c|}
\hline \multicolumn{3}{|c|}{ Father- Son } \\
\hline Characteristics & Number & Percentage \\
\hline Connecting Stroke & 45 & 86.53 \\
\hline Pressure & 30 & 57.69 \\
\hline Pen lifts & 45 & 86.53 \\
\hline Shading & 44 & 84.61 \\
\hline Diacritics "i" & 37 & 71.15 \\
\hline Diacritics "t" & 36 & 69.23 \\
\hline Loops "e" & 25 & 48.07 \\
\hline Loops "l" & 35 & 67.30 \\
\hline
\end{tabular}

Table 5: Representing correlation of handwriting characteristics between Father and Son

\section{Discusion}

After manually analyzing all the samples of 50 families, there were similarities found between the parents and the off springs.

While analyzing the general correlation of handwriting characteristics between the parents and the off springs, it was found that there is highest level of similarity in entry strokes (80\%). Apart from this, the characteristics such as exit stroke, alignment and pen lifts have $76 \%$ similarity and shading (74\%) also show a high level of similarity. However, there is only $14 \%$ similarity in the pressure applied while writing. Likewise, the loop of the letter "e" (18\%) and baseline (28\%) also show a low level of similarity [11$14]$.

While analyzing the correlation of handwriting between the Mother and Daughter, it was found that exit strokes show $87.5 \%$ and entry strokes show $83.33 \%$ similarity. Apart from these, the characteristics such as alignment (79.16\%), shading (79.16\%) and connecting stroke (77.08\%) also show a high level of similarity [15]. However, there was only $29.16 \%$ similarity found in pressure applied while writing. Likewise, the diacritic of the letter "i" (47.91\%) also shows a low level of similarity [16-17].

While analyzing the correlation between the Mother and Son, it was found that both exit strokes and entry strokes show $90.38 \%$ similarity. Apart from these, the characteristics such as alignment (88.46\%), shading (86.53\%) and connecting strokes (82.69\%) also show a high level of similarity. However, there was only $50 \%$ similarity found in pressure applied while writing. Likewise, baseline (59.96\%) also shows a low level of similarity as compared to other characteristics.

While analyzing the correlation between the Father and Daughter, it was found that exit strokes shows $89 \%$ similarity whereas entry strokes and shading show $87.5 \%$ similarity. Apart from these, the characteristics such as alignment (79.16\%) and connecting strokes (72.9\%) also show a high level of similarity. However, loop formed by the letter "e" shows a low level (43.75\%) of similarity [18]. Likewise, there was only $52.08 \%$ similarity found in loop formed by the letter "l" and $58.33 \%$ in the baseline.

While analyzing the correlation between the Father and Son, it was found that entry strokes show $92.30 \%$ similarity whereas exit strokes show a similarity of $88.46 \%$. Apart from these, characteristics such as connecting strokes (86.53), alignment (84.61\%) and shading (84.61\%) also show a high level of similarity. However, there was only $48.07 \%$ similarity found in the loops formed by the letter "e". Likewise, the baseline (50\%) and pressure (57.69\%) also show a low level of similarity [19].

The characteristics like entry strokes, exit strokes, pen lifts, connecting strokes, alignment and shading that show a high level of similarity are class characteristics whereas the handwriting characteristics such as pressure, diacritic of the letter " $\mathrm{t}$ ", loop formed by the letter " $\mathrm{e}$ ", diacritics of the letter "i" and baseline that show a low level of similarity are individualistic i.e. they vary for each person [20-22].

\section{Conclusion}

The highest percentage of similarity was found in the characteristics entry stroke among father and son (92.30\%) followed by mother and son $(90.38 \%)$ and then father and daughter (89\%) and at last mother and daughter (83.33\%).

The lowest percentage of similarity was found among characteristics such as pressure among mother and daughter and mother and son whereas among father and daughter and father and son the characteristic feature loop had least similarity.

\section{References}

1. McKeever WF (2000) A new family handedness sample with findings consistent with X-linked transmission. Br J Psychol 91: 21-39.

2. DeFries JC, Johnson RC, Kuse AR, McClearn GE, Polovina J, et al. (1979) Familial resemblance for specific cognitive abilities. Behav Genet 9: 23-43.

3. Vaibhav S, Suneet K, Syeed A, Gupta AK (2013) Similarities of Slant in Handwriting of Close Genotypic Family Members. International Journal of Computer and Electronics Research 5: 648-50. 
4. Monika S (2015) Impact of Heredity and Environment in Familial Similarity of Handwriting. International Journal of Computer and Electronics Research 4: 1-10.

5. Kramer E, Lauterbach CE (1928) Resemblance in the Handwriting of Twins and Siblings. J Educ Res 18: 149-52.

6. Bulacu M, Schomaker L, Vuurpijl L (2003) Writer identification using edge-based directional features. International Conference on Document Analysis and Recognition 7: 937-41.

7. Kam M, Westein J, Conn R (1994) Proficiency of professional document examiners in writer identification. J Forensic Sci 39: 5-14.

8. Kam M, Feilding G, Conn R, (1997) Writer identification by professional document examiners. J Forensic Sci 42: 778-86.

9. Kam M, Feilding G, Conn R (1998) The effects of monetary incentives of document examination by non-professionals. J Forensic Sci 43: 1000-4.

10. Saran V, Kumar S, Ahmed S, Gupta AK (2013) Computational method for forensic verification of offline signatures. IOSR JCE 14: 81-83.

11. Kam M, Gummadidala K, Feilding G, Conn R (2001) Signature authentication by forensic document examiners. J Forensic Sci 46: 884-8.

12. Kam M, Lin E (2003) Writer identification using handprinted and non-handprinted questioned documents. J Forensic Sci 48 : $1391-5$.

13. Sita J, Found B, Rogers D K (2002) Forensic Hand-Writing Examiners' Expertise for Signature Comparison. J Forensic Sci 47: $1117-24$.

14. Srihari SN, Cha SH, Arora H, Lee S. (2002) Individuality of Handwriting. J Forensic Sci 47: 856-72.

15. Srihari S, Huang C, Srinivasan H (2008) On the Discriminability of the Handwriting of Twins. J Forensic Sci 53: $430-46$.

16. Yaraskavitch L, Graydon M, Tanaka T, Ng LK. (2008) Controlled electrostatic methodology for imaging indentations in documents. Forensic Sci Int 177: 97104.

17. Seema K, Vaishnavi N, Shweta K (2015) Personality Identification through Handwriting Analysis: A Review. IJARCSSE 5: 548-56.

18. Qi Y, Hunt BR (1995) A multi-resolution approach to computer verification of handwritten system. IEEE Trans. Image Processing 4: 870-4.

19. Gilbert AN, Wysocki CJ (1992) Hand preference and age in the United States. Neuropsychologia 30: 601-8.

20. Maarse FJ, Schomaker L, Teulings HL (1988) Automatic identification of writers. Human-Computer Interaction: Psychonomic Aspects 353-60.

21. McKeever W F (1979) Handwriting posture in lefthanders: Sex, familial sinistrality and language laterality correlates. Neuropsychologia 17: 429-44.

22. Coll R, Fornés A, Lladós J (2009) Graphological analysis of handwritten text documents for human resources recruitment. 10th International Conference on Document Analysis and Recognition 1081-5.

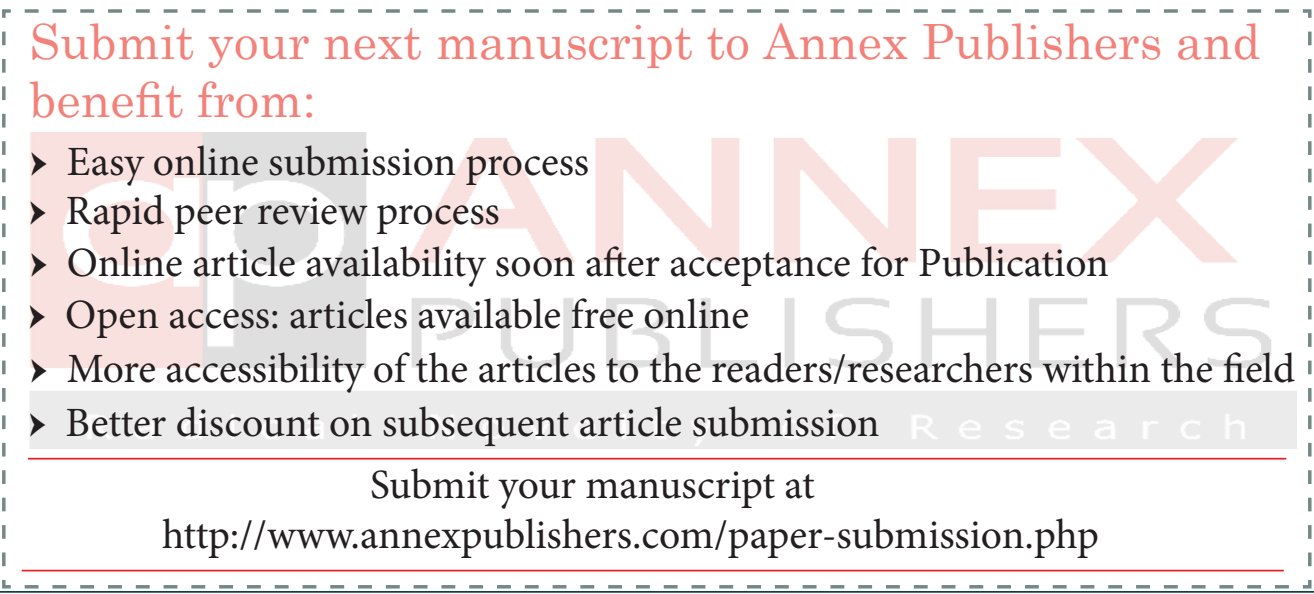

